\title{
Analysis on the Influence of the Introduction of NetsUnion on the Third-party Payment and UnionPay in China
}

\author{
Qiudan Xing, jia Hei*, Liuye Pu \\ Shaanxi normal University International Business School
}

\begin{abstract}
This paper deeply analyzes the impact of the network on the launch of the third party payment institutions, analyzes the balance of treasure of the bank card fast payment and Alipay respectively, and finally conducts an in-depth analysis of the network of UnionPay. By means of the literature research method, data collection and simple descriptive statistics, conclusions are reached as follows: (1) CAS is coming soon, which will promote the benign development of the third party payment institutions and effectively avoid the malignant competition in the market. (2) The bank card shortcut payment reduces the cost of the small and medium banks butting the payment institutions, and provides a number of various business innovations for the bank through the network of the Internet connection to the banking system. On the basis, in the future, the withholding channels will obtain compliance channels, which will become "Commercial commission payment" or "commercial commission payment". For UnionPay, the new liquidation model is bound to impact the online business of UnionPay, promote its service quality and accelerate the transformation.
\end{abstract}

Keywords - Third Party Payment; NetsUnion; UnionPay Direct connection; Broken direct connection

\section{INTRODUCTION}

It is a general trend for the society to move towards a cashless age. With the increasing of the overall scale of e-commerce and the acceleration of commodity circulation in logistics system, electronic payment has become the cornerstone of e-commerce platform. Mobile payment is booming, with Alipay and WeChat's QR code payments raging across the streets, such as hotels, restaurants, supermarkets and even street vendors. This mobile payment experience is gratifying. On the one hand, it is satisfied with the consumption habits of users, on the other hand, it also contributes to the development of enterprises.

Third-party electronic payments are booming and expanding rapidly, with the rise of third-party payments, led by Alipay and WeChat, accounting for 90 percent of the payment market. Alipay and other tools can be directly linked to a number of banks, bypassing UnionPay itself, almost formed its own clearing platform. In this case, the central bank, UnionPay and banks are unable to grasp its capital flow and information flow, forming a blind zone of supervision. The free development of third-party payment leads to a series of problems such as law, security, anti-money laundering, network fraud and so on. In addition, it also gives the central bank supervision, policy adjustment, data analysis and other financial work belt. There is a great hindrance. Based on this background, the central bank must take supervision and control measures to regulate the payment market pattern, so there is the formation of the NetsUnion settlement platform.

\section{CURRENT SITUATION OF DEVELOPMENT OF}

THIRD-PARTY PAYMENT, NETCOUPLET AND UNIONPAY IN CHINA

\section{A. Development status of third-party payments}

The third party payment platform mainly through information technology, communication technology and so on, establishes the connection in the consumer and the merchant question, plays the credit safeguard function, provides the money payment, the cash transfer, the fund settlement and so on service for the buyer and seller[1]. Under the background of the rapid development of e-commerce in China, third-party payment is developing very quickly. Alipay and Wealth Link have won the recognition of banks and other partners.

At this stage, the scale of third-party payment users in China is expanding, the transaction amount is growing rapidly, Alipay and Tenpay are "the two largest companies"[2]. In 2014 , the total capital for third-party Internet transactions in China reached 8.0767 trillion yuan. The corresponding year-on-year growth rate was $50.3 \%$, which, if maintained, would bring the total amount of third-party payment transactions to 22 trillion yuan in 2018[3].

In May 2011, the central bank issued the first third-party payment agency license. This means that online businesses paid by third parties can bypass UnionPay's direct docking of banks and build their own platform systems. 90 percent of online businesses do not go through UnionPay, and there is less regulation by clearing houses about the flow of money outside the banking system. Third-party payment agencies seize the customer's information flow, capital flow, self-development, and rapid proliferation, breeding, resulting in a series of legal, capital and network security issues, such as personal information leakage, network fraud, anti-money-laundering and so on.

In a word, the emergence of third-party payment platform has established an efficient and convenient payment channel 
for merchants and consumers, and effectively solved the needs and problems of e-commerce payment, while it also has its own defects. For example, the imperfect legal system, the loophole of safety technology and the disordered competition in the market restrict its further promotion and application.

\section{B. Development Status of UnionPay}

On April 1, 2018, China UnionPay issued a formal announcement. In order to fully implement the requirements of the relevant regulatory documents of the people's Bank of China, China UnionPay signed a cooperation agreement with Tenpay payment Technology Co., Ltd. Officially develop WeChat Pay bar code payment business cooperation. UnionPay provides a referral clearing service for the bar code payment business in WeChat Pay and plans to provide a referral settlement service to other institutions. According to the statistics of the e-commerce research center website, a number of units including the first batch of silver merchants, Everbright, and Tonglian have opened WeChat payment services through UnionPay, and Lacara, Yinsheng, CITIC, and Bank of Communications have also successively opened WeChat payment services through UnionPay.have also started WeChat Pay business through UnionPay one after another.

According to official figures from UnionPay, more than 70 payment agencies have already docked with UnionPay, some of which are in a docking state, while more than a dozen major institutions, including hundreds of member organizations, have reached a consensus with UnionPay. The national commercial banks that access the new generation of card free payment platform of UnionPay have all been launched to support the new customers of the order receiving organizations to initiate the quick payment service. More than half of the systems and business readiness to initiate payment services to existing customers. 180 or more regional banking systems have been put into production at a rate of more than 85 .

In addition to the $\mathrm{QR}$ code payment business, the development data of UnionPay's mobile phone flash payment products show that, as of the first quarter of 2018, there were 138 access banks, 113 debit cards, 85 credit cards, and the number of off-line POS terminals continued to grow. More than 10 million active users per month, more than 4700 million cards issued, 7 million live cards per month.

\section{The Current Situation of the Development of NetsUnion}

NetsUnion clearing platform of non-bank payment organization is called "network version of UnionPay" (hereinafter referred to as "NetsUnion"). There are five main services, namely, quick payment, collection / withholding, gateway payment, direct payment and payment / merchant settlement. All types of payment business will not change. What the NetsUnion does is to change the liquidation process, to cut off the direct payment mode between the bank and the third party, and it is only to change the original non-conforming liquidation process of the direct connection. The product experience for end users does not change.

Judging from the proportion of shareholders' contribution of NetsUnion Clearing Corporation (NUCC), the larger third-party payment companies have taken a stake in NetsUnion platform, as shown in Fig.1.

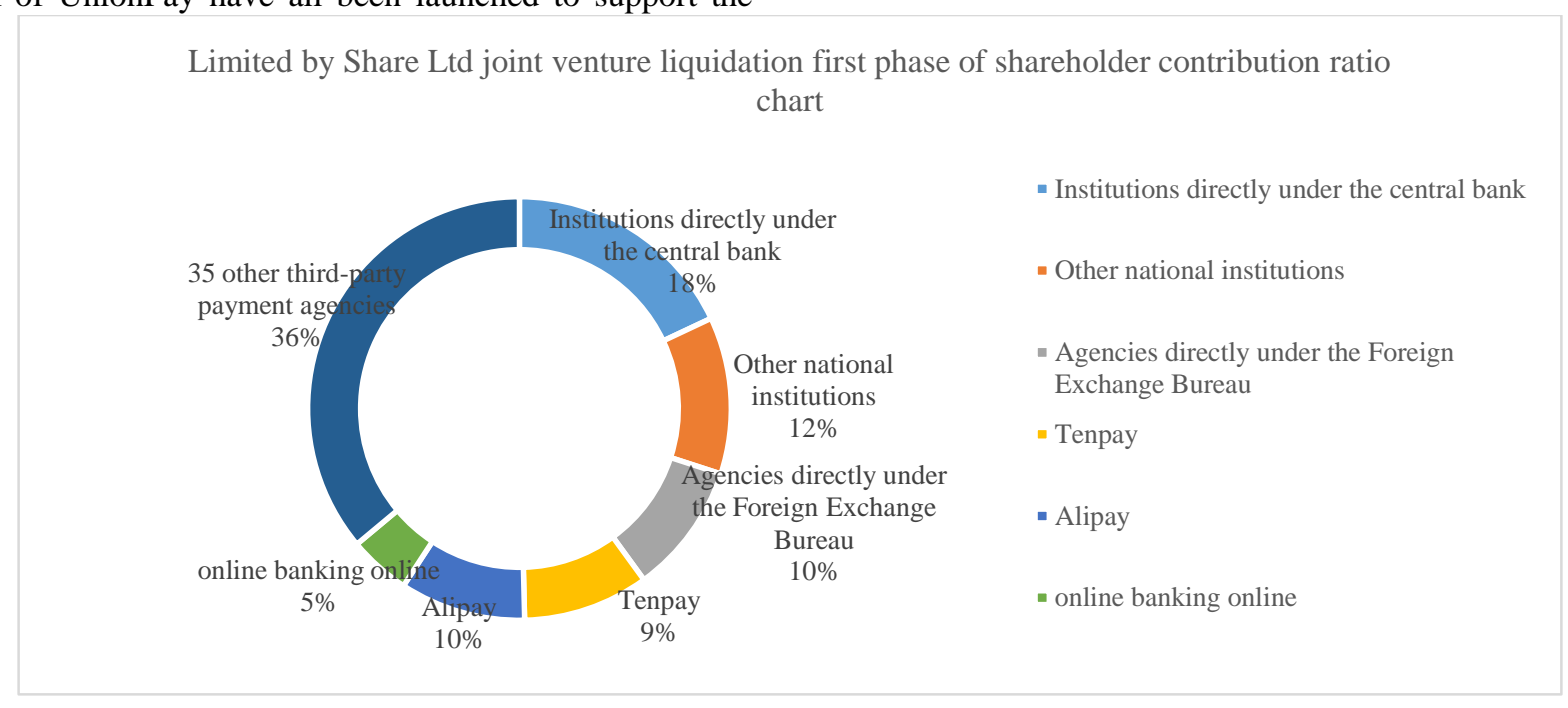

Fig. 1 Proportion of shareholders' capital contribution of Net-Lien liquidation Co., Ltd.

Because of the number of institutions, the shares held by the central bank will be relatively scattered. The central bank will also hold shares in the Internet connection platform through its direct agencies, bringing the entire payment system under formal supervision. Third-party payment company shares, so that the company in compliance with regulatory tasks, third-party payment industry as a spokesman for the interests.
In the future, the platform will build an information hub based on the industry infrastructure, strengthen the comprehensive statistics of the financial industry and share regulatory information, and form an important grasp of the financial "double opposition". To provide necessary carriers and tools for the effective supervision of the people's Bank of China and other departments, to strengthen the convenience and effectiveness of financial supervision, to prevent and 
control systemic risks, and to become the key force to maintain the national financial security and stability.

In the face of many characteristics and challenges of the new payment industry, the NetsUnion platform is fully based on the advantages of the underlying services and industry hubs of the financial infrastructure, driven by a comprehensive innovation of ideas, technologies, standards, and path models, after a year of efficient construction. Has gradually realized the established design objectives, began to play a leading role in the development of industry norms [4].

From the access data, the network access work has been quite high degree of completion. As of April 22, 2018, the platform has access to 344 commercial banks and 109 payment agencies, and is stepping up access to the remaining 110 commercial banks and 6 payment institutions. Can cover more than $95 \%$ of bank accounts more than $99 \%$ of the payment accounts, fully cover the direct mode of banking and institutional channels.

Based on the series of preparations for system docking, joint debugging testing and production verification in the early stage, NetsUnion and Tenpay signed a bar code business cooperation agreement, which has provided full access to market institutions for openness and access; at the same time, the network platform It is also steadily advancing cooperation with Alipay. Judging from the successive release of the No.42 and No. 49 articles, the "disconnected and connected" mission of NetsUnion is in an intense sprint stage. Under this background, the payment industry has also become more formal. The network-linked platform actively promotes the access of institutions on the receiving side. The cooperative institutions cover mainstream market institutions including 18 national joint-stock commercial banks and more than 10 large-scale payment institutions, such as China Construction Bank, Ping An Bank, and YeePay, China CITIC Bank and other agencies have completed the launch of NetsUnion platform, and the remaining banks and payment agencies are currently working on development and joint adjustment.

\section{THE IMPACT OF THE INTRODUCTION OF NETSUNION ON THIRD-PARTY PAYMENT}

Before that, third-party payment institutions assumed the liquidation business on their own and followed the direct link mode, which made transactions opaque and not public. Banks could not grasp the comprehensive trading data of consumers, and the central bank was unable to master accurate capital flows. In financial regulation and monetary policy adjustment and other work difficulties. And many payers use eating spreads as the main profit model, as shown in figure 2.

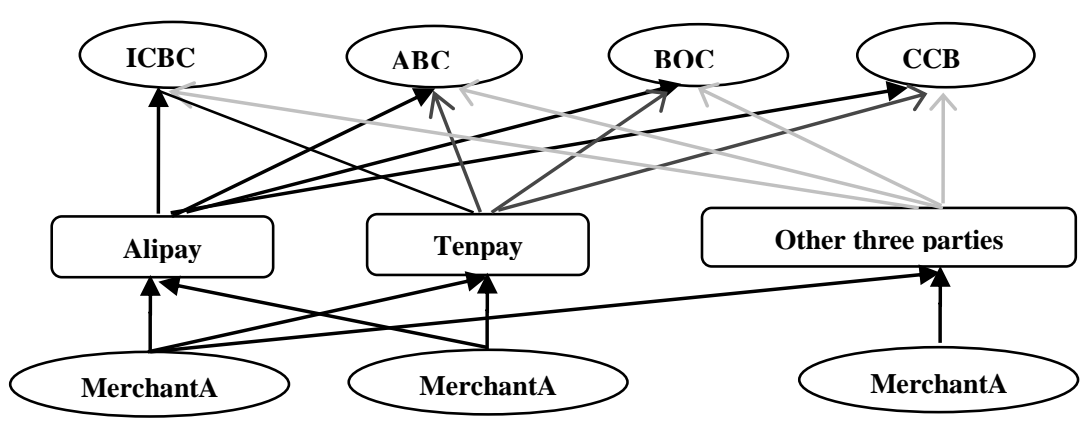

Fig. 2 Direct connection Mode of Third-party payment and Internet Banking

To put it simply, the direct connection mode is that in the scenario of barcode payment acceptance, the flow of funds follows the pattern of "Alipay/WeChat $\rightarrow$ Banking Service

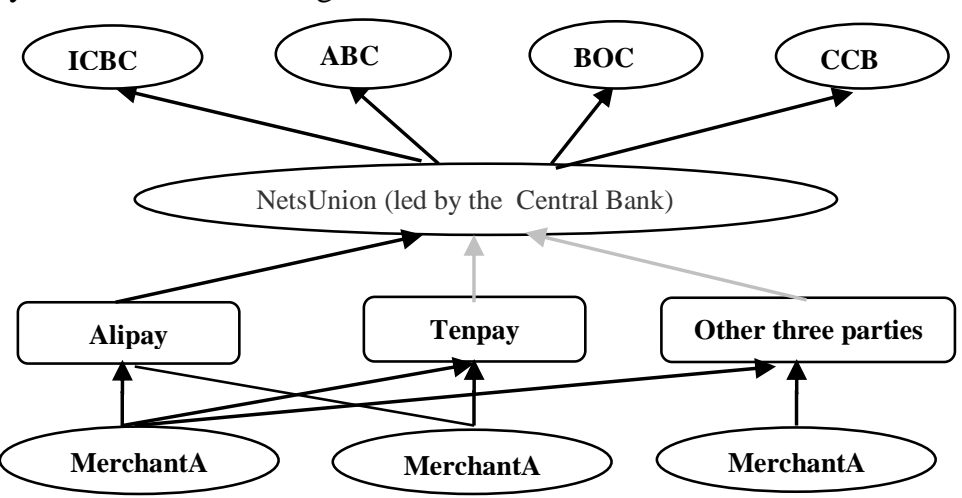

Fig. 3 Network connection mode (the disconnected mode of third-party payment and online banking)

As shown in figure 3 , the network connection mode (the "direct connection" mode of third-party payment and banking,
Providers - Acquiring Institutions $\rightarrow$ Merchants". Third-party payment agencies directly establish cooperation with various banks.

that is, when the bank closes the direct withholding channel of the third-party payment institution, will be added to the 
original transaction path link. The trading path became "Alipay / WeChat net couplet-the order-receiving agency merchants." The online operations of Alipay, Tenpay and other tripartite payment agencies are all connected to each bank through the Internet connection. For payment agencies, it may be possible to open a single bank account in the future to handle all cash and receipts for customers.

NetsUnion acts as a clearing service, avoiding third-party payments working directly with banks, which weakens the bargaining power of large payers and gives smaller payment agencies the opportunity to compete equally on third-party payment platforms of any market size. Can choose the best rate of banks to cooperate. This has a good role in promoting the benign development of third-party payment institutions. It can regulate the industry behavior of the payment market reasonably, and promote the healthy and orderly development of third-party payment. Effectively avoid the vicious competition that may exist in the payment market, and prevent the misappropriation of reserve, network fraud, anti-money laundering and other adverse events.

\section{A. The influence on the Quick payment of Bank Card}

For banks, it is likely that more attention will be paid in the future to whether clearing data can be shared. After the introduction of NetsUnion, the unified management of reserves will make small and medium-sized banks lose this derivative business income, but also benefit from it. Small and medium-sized banks no longer have to spend a lot of money docking more than a hundred payment agencies. Once connected to the Internet, they can share the many consumption scenarios of payment agencies and e-commerce platforms and promote innovation in retail business. It provides a data base for banks to carry out all kinds of business innovation through the user transaction data flowing to the banking system.

In addition, through the Internet platform to complete the liquidation of the "quick payment" will be changed to "agreement payment", "collection withholding" will also become "commercial commission payment." In terms of the concept interpretation of the network federation, "agreement payment" is the future of "quick payment" in the direct connection mode, and the bank's withholding channel will also be connected to the liquidation organization similar to the network federation, and the future payment channel will be able to obtain compliance channels from the network federation. That is to say, "commercial commission payment".

\section{B. Impact on Alipay Account}

According to the notice of the people's Bank of China on standardizing payment innovation business, in order to strengthen the management of payment business system interface, it is stipulated that banks and payment institutions cannot open and transfer payment business system interfaces to each other. This will not represent the future receipt of orders may be through the network this transit station, and then received Alipay up.

The interface for banks and payment institutions is a network connection, from $\mathrm{N}$ to 1 . Under the direct connection mode, the bargaining right of the giant payment organization Alipay disappeared, while the small and medium-sized payment organization with weak bargaining power enjoyed the flat rate and the cost was reduced. The network federation unifies manages the reserve fund, this has greatly reduced the customer reserve fund management difficulty and the cost, but also means the third party payment organization to rely on the reserve fund to obtain "the hidden income" to reduce. For Alipay, although the loss of reserve, but its consumption scenario under a large number of financial business, reserve interest income is not high. In addition, direct connection What is more, it is aimed at the two major giants of Alipay and Tenpay. In the face of the collection of the two major liquidation institutions, Alipay and Tenpay will have an impact on their development by handing over the liquidation business to whom. Under the background of the net and UnionPay game, the two giants, Alipay and Tenpay, are bound to play the game, which will intensify the competition between the two giants to a certain extent.

\section{Impact on Yu'e Bao Account}

Earlier, Mr. Ma launched Yu'e Bao, encouraging Alipay users to keep their spare money in Yu'e Bao, which allows users to receive a good monthly profit from their spare money. Users invest short-term idle funds into Yu'e Bao, which is generally based on the consideration of reducing the cost of holding funds, and is a short-term investment behavior with the nature of transaction. After the introduction of the Internet Federation, Alipay should confirm a financial liability when receiving funds from customers to transfer to Yu'e Bao. If the balance of Alipay or Yu'e Bao is not formed by the bank deposit, it will not involve the liquidation of NetsUnion. If the enterprise does not withdraw the payment, it stays in the Alipay account. Household or into Yu'e Bao, also won't involve the liquidation of the network link [5]. The introduction of the Federation, in addition to the impact of Yu'e Bao's capital flow, and not much impact. 


\section{THE IMPACT OF THE INTRODUCTION OF NETSUNION ON UNIONPAY}

Both the UnionPay and UnionPay clearing houses are accredited by the central bank, and there is bound to be competition within them, which will also help UnionPay improve its service quality. The launch of the network, meaning a reshuffle of the domestic payment market, which will impact on the line of business UnionPay. The comparison between NetsUnion Clearing platform and UnionPay Cards-Free Business transfer platform is shown in Table 1.

TABLE I.

COMPARISON BETWEEN NETCOUPLET CLEARING PLATFORM AND UNIONPAY CARDS FREE CLEARING PLATFORM

\begin{tabular}{|l|l|l|}
\hline Internet clearing platform & UnionPay Cards Free Business transfer Clearing platform \\
\hline Online time & March 2017 & Mid-2017 \\
\hline DC & Three places six centers & The three centers of the two places \\
\hline Access mechanism & $\begin{array}{l}\text { Has reached 328 commercial banks } \\
\text { and 87 payment agencies }\end{array}$ & $\begin{array}{l}17 \text { national commercial banks more than } 180 \text { regional banks: more than } 100 \text { payment } \\
\text { agencies agree that more than } 70 \text { have docked or are in the process of docking }\end{array}$ \\
\hline $\begin{array}{l}\text { Shareholder } \\
\text { background }\end{array}$ & $\begin{array}{l}\text { Third party organization } \\
\text { The bank }\end{array}$ \\
\hline
\end{tabular}

From the above table, we can see that the online time of the NetsUnion clearing platform is earlier than that of UnionPay's non-card business transfer to the clearing platform. In order to support the transfer and liquidation of transactions in the world's largest network payment market, the NetsUnion platform adopts a distributed cloud computing architecture. Three, six centers, finance and other four standards, set up to achieve high security, high availability, high performance, high expansion, high controllable and high consistent system standards. As far as the access organization is concerned, the number of access is much larger than that of UnionPay, and the shareholder background of NetsUnion is mainly the third party which occupies the majority of payment market share. In other words, as an online clearing institution that focuses on supporting construction, the network federation is the one in the clearing market While UnionPay has equity relationships with third parties, UnionPay is a clearing house as well as a payer, and itself has a competitive relationship with third-party payers. Although UnionPay has more than 10 years of system construction and market experience in the liquidation field, and its service capacity in various aspects such as transaction processing speed and fund clearing efficiency is slightly superior at this stage, it is in the process of breaking up the direct connection. UnionPay has clearly lost the cutting advantage of online payments.

In short, the NetsUnion has the advantage over the line; the UnionPay occupies the advantage below the line. In order to be able to carry out business smoothly, payment organizations are bound to have access to both the network federation and the UnionPay liquidation agencies, so that the quality of service of the two payment organizations will be taken into account. In terms of stability and performance, which has the advantage of handing over the clearing business to that company, which is bound to promote UnionPay to improve its service quality and accelerate the transformation to some extent.

\section{REFERENCES}

[1] Hanlai Wan. Model Analysis and problem Exploration of third Party payment [J]. Modern information technology: 178-179.

[2] Che Liu, Xin Cai, Hongwei Peng, Li Feng. Comparison of international experience in third-party payment regulation and policy recommendations [J]. Southwest finance: 03: 42-47.

[3] Xiuli Yu. Research on the Security of third Party payment in Electronic Commerce [J]. Macroeconomic management: s1:134-135.

[4] Junfeng Dong. To build an efficient online payment clearing platform [J]. China's financial sector: 41: 46-47.

[5] Guoguang Zhou, Liyan Wen. Accounting treatment of Third-Party payment Service under Net-connection Mode-take Alipay as an example [J]. The monthly Journal of Accounting is in 2015 / 05: 77-81. 